\title{
Tightening the purse strings
}

\author{
Science budgets are being trimmed at the \\ European Space Agency. Sally Goodman talks \\ to David Southwood, the man charged with \\ deciding how the money should be saved.
}

"N obody does space science who's not an optimist - it's a requirement of the job," observes David Southwood with a wry smile. It is just as well that Southwood, director of science at the European Space Agency (ESA), feels this way. As a space physicist at Imperial College London, he worked on the Cassini mission to Saturn. Now he is responsible for implementing cuts to the very programme that helped to fund ESA's contribution to that project.

Southwood took over as science director last May when astrophysicist Roger Bonnet stepped down after 18 years in the job. He knows ESA well, having chaired the agency's space-science advisory committee and coordinated its Earth observation strategy.

But just months into his new role, Southwood's political paymasters have handed him a budget of 1.869 billion euros (US $\$ 1.62$ billion) - 76 million euros less than he had hoped for (see Nature 414, 383; 2001). Science budgets have fallen $15 \%$ in real terms over the past six years, he says, and this seriously threatens the breadth of ESA's research.

\section{Recycling project}

Southwood now faces the thankless task of deciding how to cut ESA's science programme, for which he has imposed a deadline of June. Money will be saved by reusing hardware developed for other missions. Further collaborations with other space agencies are also on the cards. And a single big mission could still be sacrificed.

But whatever path he chooses, Southwood knows that his decisions will affect hundreds of researchers - many of whom might find it difficult to accept that missions that reuse hardware may win out over others with stronger scientific backing. He says that he is keeping in with his old career by doing a little research when he has the time, but readily admits that the difference now is that "the buck stops here".

Reusing equipment is a tried and tested method of reducing mission costs, but it can complicate schedules. Solar Orbiter, an ESA spacecraft that would observe the Sun from as close as 0.2 astronomical units ( $1 \mathrm{AU}$ is the distance between the Earth and the Sun), is a case in point. To reduce costs, Solar Orbiter will use technology being developed to help another ESA spacecraft - BepiColombo to cope with the high temperatures it will experience on its journey to Mercury.

But BepiColombo will not fly until 2009. So Solar Orbiter's launch must wait until then at the earliest, and could be delayed beyond this date. The industrial teams working on BepiColombo will be disbanded soon after the earlier mission's launch, further complicating matters. Such uncertainty affects the careers of researchers working on the mission. "I have students working on prototypes of instruments for Solar Orbiter," says Ester Antonucci of the Astronomical Observatory of Turin. "But I can't keep them by offering prototypes. To make a career they need to build instruments."

Southwood counters

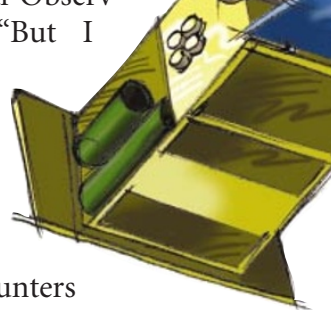
that any decisions on launch dates must incorporate cost considerations. "Scheduling isn't simply by scientific priority," he says. Other missions will have to reuse equipment, he insists. He cites the example of Venus Express, ESA's proposed 2005 mission to Venus, which is designed specifically to use the same type of bus - the aluminium shell that holds the instruments - as the agency's 2003 Mars Express mission.

\section{Mix and match missions}

Another solution will be to fill gaps between ESA missions by targeting opportunities in other agencies' projects. European 'space weather' researchers are already working on Stereo, a NASA mission slated for a 2004 launch that will study matter ejected from the Sun. Solar physicists are involved in Japan's 2005 Solar-B probe, which will take high-resolution images of the Sun from an Earth orbit. "The solar physics community can't be dependent on just one agency," says Richard Harrison of the Rutherford Appleton Laboratory near Oxford.

Despite such steps, whole missions may still have to go. After the budget announcement, Southwood publicly stated that GAIA, an ambitious mission to map around $1 \%$ of

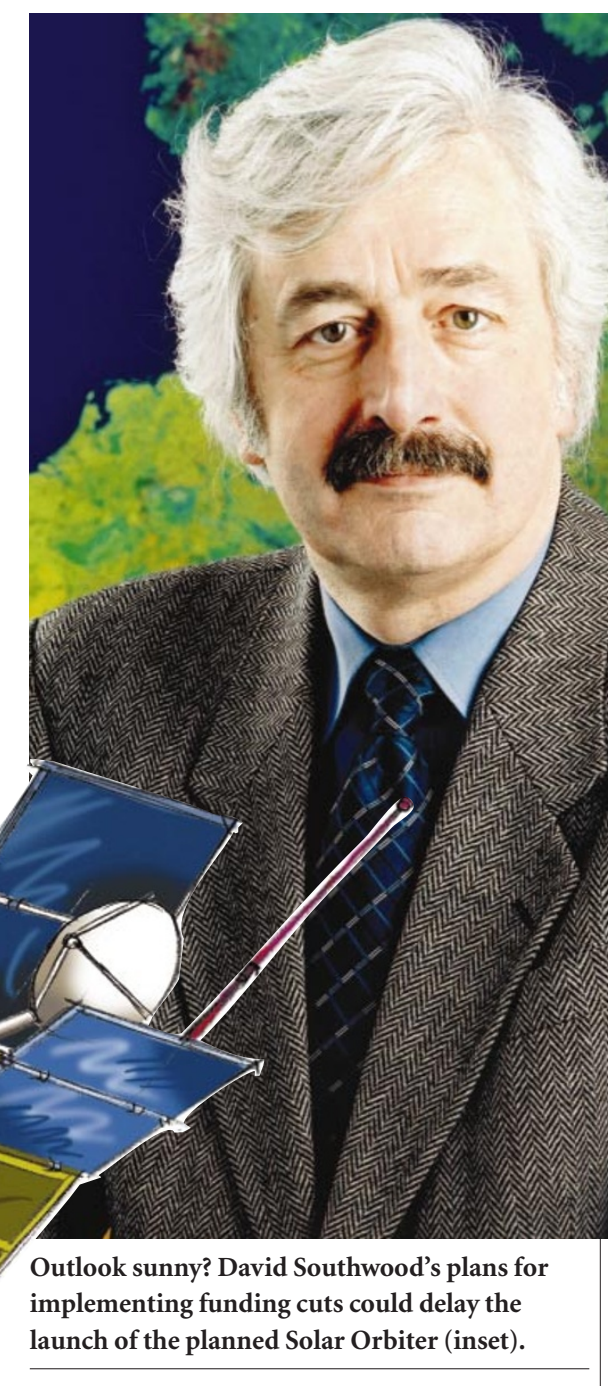

our Galaxy's stars, was in jeopardy. "I decided to make it clear to ministers, to choose an example, rather than talk in generalities," he explains.

But such talk could turn researchers off the project and become a self-fulfilling prophesy. Gerry Gilmore, a member of GAIA's science advisory group based at the University of Cambridge, UK, already says he would deter students from working on GAIA if the schedule slips, for fear of ruining their careers.

Southwood seems painfully aware of the impacts that his statements can have. "My biggest challenge is keeping the community feeling they've got the best programme for the money," he says. "I don't want disaffected members feeling they've been shortchanged."

But cutting costs will inevitably leave some researchers feeling disaffected - a problem only a budget increase is likely to end. In the long term, Southwood hopes that ESA member states will reconsider when they see what cuts mean in practice. "A space agency without a flourishing science programme," he says, "is not fulfilling one of the human aspirations people have for it." Sally Goodman is Nature's French correspondent. http://sci.esa.int 